\title{
Apolipoproteins A-I and B and the B/A-I Ratio in the First Year of Life
}

\author{
X. L. WANG, D. E. L. WILCKEN, AND N. P. B. DUDMAN \\ Department of Cardiovascular Medicine, University of New South Wales, The Prince Henry/Prince of Wales \\ Hospitals, Sydney, New South Wales, Australia
}

\begin{abstract}
To investigate early detection of young families with inherited dyslipidemia, we assessed changes in circulating apolipoprotein (apo) $B$ and A-I levels and the apo B/A-I ratio during the 1 st year of life and their relations to parental values. After measuring initial dried blood spot capillary blood levels in 919 babies when aged $4.25 \pm 0.98$ $d$ (mean $\pm \mathrm{SD}$ ), we recalled at a mean age of $8.5 \pm 2.3$ mo those with levels in one or more of the following categories: the top $5 \%$ of apo B values (group 1), the top $5 \%$ of apo B/A-I ratios (group 2), the bottom $5 \%$ of apo A-I values (group 3), and a group of 18 infants (group 4) who were not in any of the above three categories. We thus obtained serum lipid measurements in $\mathbf{5 1}$ infants and their parents. Two of the 13 group 1 infants had persistent hyperapo $B$ at $8.5 \mathrm{mo}$; there was an inverse relationship between apo $B$ and apo A-I levels in this group $(p<0.001)$. Two of 11 babies in group 2 had lipid profiles consistent with familial hypercholesterolemia. However, none of the infants in group 3 had evidence at 8.5 mo of abnormal apo A-I or HDL levels, nor did their parents. For groups 1, 2, and 3, there was at $8.5 \mathrm{mo}$ a regression of apo $B$ and $A-I$ toward mean levels for the "normal" 18 babies of group 4 . In contrast, the high apo B/A-I ratios in group 2 remained high $(p<0.01)$ and showed evidence of tracking. Correlations between birth weight and apo $B$ (positive) and apo A-I (negative) that were found previously at 1 wk were still evident at $8.5 \mathrm{mo}$. Thus, individual apo B/A-I ratio measurements during the 1 st week of life are predictive of levels at $8.5 \mathrm{mo}$, and this finding may facilitate familial hypercholesterolemia detection. Persistence of significant correlations between birth weight and apolipoprotein levels suggests an ongoing relationship between birth weight and subsequent lipid metabolism. (Pediatr Res 30: 544-549, 1991)
\end{abstract}

Abbreviations

apo $A-I$, apolipoprotein $A-I$

apo $B$, apolipoprotein $B$

apo(a), apolipoprotein(a)

In a recent study we measured apo A-I, the principal protein moiety of the antiatherogenic HDL cholesterol, and apo B, the carrier protein for the atherogenic LDL cholesterol, in 919 consecutively born neonates of birth weights $2 \mathrm{~kg}$ or greater when they were 2 to $5 \mathrm{~d}$ old (1). We wished to assess the variables affecting both of these apolipoproteins in the neonatal period

Received January 3, 1991; accepted July 22, 1991.

Correspondence: Professor D. E. L. Wilcken, Department of Cardiovascular Medicine, Clinical Sciences Building, The Prince Henry Hospital, Little Bay, N.S.W. 2036, Australia.

Supported by the National Heart Foundation of Australia. and to explore the hypothesis that the ratio of apo B to A-I when measured in dried blood spots obtained during routine neonatal screening programs could identify families with genetically determined dyslipidemias associated with increased cardiovascular risk. Levels of these apolipoproteins may be better predictors of coronary risk than HDL and LDL cholesterol (2-4). Our ultimate aim is to facilitate family-based coronary prevention directed to young parents with dominantly inherited dyslipidemia in the expectation that this would also benefit the children themselves when older (5). Our studies showed that birth weight, day of sampling (between $\mathrm{d} 2$ and 5 after birth), and sex, in the case of apo $\mathrm{B}$, all influenced the measured levels (1).

Our aims in the study presented here were to assess the initial birth weight effects on the infants' apolipoprotein levels when they were approximately 8.5 mo of age and to explore correlations between the neonatal and the later concentrations and the relevance of levels in the infants and their parents to the detection of familial dyslipidemia. Our hypothesis was that the ratio of B to A-I would be a better marker for familial dyslipidemia than the measurement of apo B alone, which we had used in earlier studies $(6,7)$.

\section{SUBJECTS AND METHODS}

We sent letters to parents of four groups of infants, from a total of 919 babies assessed previously during the 1st week of life (1), when the babies were of mean age 8.5 mo proposing lipid measurements in the infants and their parents.

To define the infant groups, we first adjusted the measured neonatal apolipoprotein levels for the variables we had previously shown to affect them including birth weight, age at sampling, and sex in the case of apo B (1). Birth weight, a major contributor to variability, correlated negatively with apo A-I levels and positively with apo B levels (1). Age at sampling, between the 2nd and 5th postnatal days, was positively correlated with the levels of both apolipoproteins. We adjusted apo B level according to our finding that, for a given age and birth weight, values for females are on average $9 \%$ higher than for males $(1,6)$.

Having adjusted for birth weight, age at sampling, and sex, we selected infants whose neonatal apolipoprotein levels were in one or more of the following groups: the top $5 \%$ of the apo B distribution; the top $5 \%$ of the apo B/A-I distribution; and the lowest $5 \%$ of the apo A-I distribution. A fourth group of 18 infants with apolipoprotein levels not included in any of above three groups was also selected. These 18 infants had neonatal apo A-I above the 5th percentile and neonatal apo B and apo B/ A-I below the 95th percentiles of their distributions.

Recall of babies with high neonatal apo $B$. The 95 th percentile for the adjusted apo B level in these 919 neonates was $0.46 \mathrm{~g} / \mathrm{L}$ of whole blood, the equivalent of $1.01 \mathrm{~g} / \mathrm{L}$ in serum assuming a hematocrit of $55 \%$. Of the 45 neonates whose apo B levels were in the top 5\%, 13 families responded and provided samples from 13 infants, 12 mothers, and 10 fathers. They formed infant group 1 in the analysis. 
Recall of babies with high neonatal apo B/A-I. The 95th percentile for the ratio was 1.3. Among the 45 neonates with ratios above this level, 14 also had apo B levels in the top $5 \%$ of that distribution. There were, therefore, 31 neonates with high apo B/A-I ratios separate from those within the apo B top $5 \%$; 11 of these families responded and 11 mothers, 11 fathers, and 11 babies provided samples. They form infant group 2 in the analysis.

Recall of babies with low neonatal apo A-I. There were 45 neonates in the lowest $5 \%(<0.21 \mathrm{~g} / \mathrm{L}$ of whole blood, the equivalent of $0.46 \mathrm{~g} / \mathrm{L}$ of serum assuming a hematocrit of $55 \%$ ) of the distribution of the adjusted concentration among the 919 neonates assessed. When those who were also among the top 5\% of the apo B or apo B/A-I distributions were excluded, there remained 29 neonates with isolated low initial apo A-I. Letters were sent to the parents of all 29. Nine of these families responded, and we obtained venous samples from nine mothers, eight fathers, and nine infants. They form infant group 3 in the analysis.

Thus, of the 76 families whose infants had high neonatal apo B or apo B/A-I ratios, 24 (32\%) were available for study and, of the 29 infants with isolated low neonatal apo A-I, nine families $(31 \%)$ were available.

Recall of babies with "normal" neonatal apo $B, A-I$, and $B / A$ $I$. Eighteen other babies who had neonatal apo B levels and apo $\mathrm{B} / \mathrm{A}-\mathrm{I}$ ratios below the 95 th percentile and neonatal apo A-I levels above the 5th percentile also attended the study with 17 of their fathers and 18 of their mothers. They constitute infant group 4 in the analysis. These infants were from among 50 recalled separately because of increased apo(a) levels. Because we had previously shown apo(a) levels to be independent of apo B and apo A-I levels in this population in the neonatal period (1) and they were also independent of them in the present population, we compared the apo B and apo A-I changes in these group 4 infants with the changes in those who had high neonatal apo B, high apo B/A-I, and low apo A-I. The total study group, therefore, comprised 51 infants and 97 of their 102 parents.

Sample collection and apolipoprotein assays. Venous blood samples were taken after a 12 -h overnight fast in parents and after a recommended 6-h nonfeeding period in the babies. Measurements of total cholesterol, HDL cholesterol, LDL cholesterol (by calculation), and triglycerides were performed by the hospital's Clinical Chemistry Department, and separate aliquots of parents' and infants' clotted blood were received in our laboratory within $4 \mathrm{~h}$ of venipuncture. The sera were immediately separated and stored at $-70^{\circ} \mathrm{C}$ for lipid and apolipoprotein analysis. The infants' serum total cholesterol, HDL cholesterol, LDL cholesterol (by calculation), and triglyceride levels were measured by the Department of Biochemistry, Royal Alexandria Hospital for Children, Sydney. Apo A-I and B levels were assayed in our laboratory within $3 \mathrm{wk}$ of sampling.

Both the initial dried blood spot capillary blood apo A-I and $B$ levels and the serum concentrations measured at a mean age of $8.5 \pm 2.3 \mathrm{mo}$ (range $5-13 \mathrm{mo}$ ) were assayed by ELISA as described previously from this laboratory $(8,9)$. The within-assay and between-assay coefficients of variation for dried blood spot apo A-I measurements for the whole study were 5.4 and $7.8 \%$, respectively, and for serum apo A-I, 4.2 and $8.5 \%$, respectively. The dried blood spot apo B measurements had within-assay and between-assay coefficients of variation of 6.4 and $16 \%$, respectively, and the serum apo $\mathrm{B}$ assay, 4.7 and $8.6 \%$, respectively. The neonatal capillary blood samples were obtained by heel prick and spotted onto filter paper as part of the State of New South Wales neonatal screening program for phenylketonuria and hypothyroidism. To compare these whole blood measurements with the serum levels measured when the infants were at a mean age of $8.5 \mathrm{mo}$, we converted the neonatal whole blood concentrations to approximate serum levels by multiplying by 2.2. We assumed a hematocrit of $55 \%$ (10).
The project was approved by the Ethics Committee of the University of New South Wales.

Statistics. Because the sizes of the subgrouped samples were small and the measured variables were not normally distributed, we used the nonparametric Mann-Whitney U test to compare the measured apolipoprotein and lipid levels between different subgroups and between parents and children. We also used the Wilcoxon paired test to compare the apolipoprotein levels measured at $1 \mathrm{wk}$ and at 5-13 mo. The linear regression coefficient was used to assess relationships between babies' and parents' lipoprotein and apolipoprotein levels in all families where samples were obtained from the infants and both parents. For the assessment of correlations between measured variables, we used least squares linear regression analysis. For these correlations between the measured variables in subgrouped infants, we also used Spearman ranked correlation tests. Because the correlation coefficients by both statistical methods were virtually the same and the levels of the statistical significance of the coefficients were also not different, only the correlation coefficients by least squares linear regression method were reported.

\section{RESULTS}

Apolipoproteins and lipoproteins in infants. The mean levels \pm $\mathrm{SD}$ of apo B and A-I and the B/A-I ratio for all four infant groups in the neonatal period and at a mean age of $8.5 \mathrm{mo}$, together with their lipid profiles at $8.5 \mathrm{mo}$, are shown in Table 1. The neonatal apo B and A-I levels reported are estimated serum levels obtained by assuming a $55 \%$ hematocrit. Although there are some variations in the levels of total, LDL, and HDL cholesterols and triglyceride at 8.5 mo among the four different groups (Table 1), none of these differences was statistically significant. There were also no significant differences in the levels of apo A-I and apo B at 8.5 mo among the four subgroups. However, the apo B/A-I ratios in group 2 infants who had high initial ratios were significantly higher than in any of the other three subgroups $(p<0.001)$.

Infant group 1. Apo B decreased markedly during the 8.5-mo period $(p<0.0001)$ in the group 1 infants with neonatal apo B above the 95th percentile (Table 1). Apo A-I and apo B/A-I also decreased, but the changes were not significant (Table 1). The correlation between the two apo B measurements was poor among the 13 group 1 infants (Table 1). When apo B at 8.5 mo in group 1 and group 4 infants were compared, the later having had normal neonatal levels, the levels were similar (Table 1 and Fig. 1, top panel). There was, therefore, evidence of regression to the mean value in the initially high apo B group 1 babies.

Among these 13 group 1 babies with high neonatal apo $\mathrm{B}$, one had high total cholesterol $(7.1 \mathrm{mmol} / \mathrm{L})$, LDL cholesterol $(5.0$ $\mathrm{mmol} / \mathrm{L})$, and apo B (1.24 g/L) when aged 5 mo. The parents' levels of total and LDL cholesterol were 6.2 and $4.8 \mathrm{mmol} / \mathrm{L}$ for the father and 6.4 and $4.1 \mathrm{mmol} / \mathrm{L}$ for the mother, respectively; for apo B the levels were 1.00 and $1.07 \mathrm{~g} / \mathrm{L}$ for the father and the mother, respectively. Another baby also had an increased total cholesterol $(5.7 \mathrm{mmol} / \mathrm{L})$, LDL cholesterol $(4.4 \mathrm{mmol} / \mathrm{L})$, and apo B (1.29 g/L) at 6 mo. Only the mother came for study, and her total cholesterol $(4.3 \mathrm{mmol} / \mathrm{L})$ and apo B levels $(0.73 \mathrm{~g} /$ L) were within the normal adult range.

An interesting additional finding in these group 1 infants was that at age 8.5 mo the apo A-I and apo B levels in the 13 infants were highly negatively correlated $(r=-0.838, n=13, p=$ 0.0003 ). There was also a trend toward this negative correlation in all of the other three groups, although none achieved statistical significance (Table 2).

Infant group 2. In these infants with high neonatal apo B/A-I ratios, there was an increase in apo A-I and a decrease in apo B at $8.5 \mathrm{mo}$ so that apo B/A-I decreased; none of these changes was statistically significant (Table 1). Although apo B/A-I at these two times was not significantly correlated for group 2 infants, the apo B/A-I ratios of group 2 infants at 8.5 mo were 
Table 1. Lipoprotein and apolipoprotein profiles in infants [mean (SD)]*

\begin{tabular}{|c|c|c|c|c|c|c|c|c|}
\hline & Age† & Apo A-I & Apo B & Apo B/A-I & $\mathrm{TC}$ & TG & HDL-C & LDL-C \\
\hline \multirow[t]{2}{*}{ Group $1(n=13) \ddagger$} & Neonates & $\begin{array}{c}0.91 \\
(0.38)\end{array}$ & $\begin{array}{c}1.15 \\
(0.17)\end{array}$ & $\begin{array}{c}1.57 \\
(0.91)\end{array}$ & NA & NA & NA & NA \\
\hline & Infants & $\begin{array}{c}0.80 \\
(0.25)\end{array}$ & $\begin{array}{c}0.70 \S \\
(0.27)\end{array}$ & $\begin{array}{c}1.05 \\
(0.71)\end{array}$ & $\begin{array}{c}4.24 \\
(1.15)\end{array}$ & $\begin{array}{c}1.61 \\
(0.78)\end{array}$ & $\begin{array}{c}0.93 \\
(0.23)\end{array}$ & $\begin{array}{c}2.59 \\
(1.01)\end{array}$ \\
\hline$r$ & & $0.49 \|$ & 0.36 & 0.35 & & & & \\
\hline \multirow[t]{2}{*}{ Group $2(n=11)$} & Neonates & $\begin{array}{c}0.55 \\
(0.15)\end{array}$ & $\begin{array}{l}0.9 \\
(0.17)\end{array}$ & $\begin{array}{c}1.75 \\
(0.67)\end{array}$ & NA & NA & NA & NA \\
\hline & Infants & $\begin{array}{c}0.73 \\
(0.17)\end{array}$ & $\begin{array}{c}0.87 \\
(0.44)\end{array}$ & $\begin{array}{c}1.29 \\
(0.79)\end{array}$ & $\begin{array}{c}4.83 \\
(2.13)\end{array}$ & $\begin{array}{c}1.45 \\
(0.63)\end{array}$ & $\begin{array}{c}0.95 \\
(0.18)\end{array}$ & $\begin{array}{c}3.29 \\
(2.00)\end{array}$ \\
\hline$r$ & & 0.20 & 0.10 & 0.52 & & & & \\
\hline \multirow[t]{2}{*}{ Group $3(n=9)$} & Neonates & $\begin{array}{c}0.4 \\
(0.08)\end{array}$ & $\begin{array}{c}0.37 \\
(0.14)\end{array}$ & $\begin{array}{c}1.02 \\
(0.53)\end{array}$ & NA & NA & NA & NA \\
\hline & Infants & $\begin{array}{c}0.79 \S \\
(0.17)\end{array}$ & $\begin{array}{c}0.659 \\
(0.20)\end{array}$ & $\begin{array}{c}0.88 \\
(0.39)\end{array}$ & $\begin{array}{c}4.49 \\
(0.87)\end{array}$ & $\begin{array}{c}1.58 \\
(0.47)\end{array}$ & $\begin{array}{c}0.97 \\
(0.36)\end{array}$ & $\begin{array}{c}2.80 \\
(0.80)\end{array}$ \\
\hline$r$ & & 0.28 & 0.23 & 0.51 & & & & \\
\hline \multirow[t]{2}{*}{ Group $4(n=18)$} & Neonates & $\begin{array}{c}1.06 \\
(0.36)\end{array}$ & $\begin{array}{c}0.60 \\
(0.37)\end{array}$ & $\begin{array}{c}0.62 \\
(0.39)\end{array}$ & NA & NA & NA & NA \\
\hline & Infants & $\begin{array}{l}0.83^{* *} \\
(0.18)\end{array}$ & $\begin{array}{l}0.67^{* *} \\
(0.21)\end{array}$ & $\begin{array}{c}0.88^{* *} \\
(0.48)\end{array}$ & $\begin{array}{c}4.39 \\
(0.89)\end{array}$ & $\begin{array}{c}1.91 \\
(1.93)\end{array}$ & $\begin{array}{c}0.88 \\
(0.32)\end{array}$ & $\begin{array}{c}2.66 \\
(0.68)\end{array}$ \\
\hline$r$ & & 0.18 & $0.74 \S$ & $0.71 \S$ & & & & \\
\hline
\end{tabular}

* TC, total cholesterol; TG, triglyceride; HDL-C, HDL cholesterol; LDL-C, LDL cholesterol; and NA, not applicable.

$\dagger$ Neonates indicate those age 2-5 d; infants indicate those age 5-13 mo.

¥Infant group 1 includes infants who had initial apo B above the 95th percentile; group 2 had initial apo B/A-I ratios above the 95 th percentile; group 3 had initial apo A-I within the 5th percentile; and group 4 had initial apo A-I above 5th percentile and initial apo B and apo B/A-I ratios below the 95 th percentiles.

$\S p<0.001$.

$\| 0.10>p>0.05$.

If $p<0.01$

$* * 0.05>p>0.01$

significantly higher than those in any of the other groups $(p<$ 0.001 ). In Figure 1 (middle panel), values in all infants among these 51 babies with high neonatal apo B/A-I ( $>95$ th percentile, $n=20$ ) and group 4 infants who had neonatal apo B/A-I less than the $95 \%$ percentile are compared. The significant difference between the two groups is maintained at $8.5 \mathrm{mo}$ ( $1.38 \pm 0.78$ for infants with high and $0.88 \pm 0.48$ for group 4 infants with normal apo B/A-I, $p<0.001$ ). This finding suggests a degree of tracking of the ratios during the 1 st year of life even though the ratios in group 2 infants did decrease during this time.

In support of this, two of 11 babies assessed in the top 5\% of the apo B/A-I ratios had markedly elevated total cholesterol levels of 9.1 and $8.8 \mathrm{mmol} / \mathrm{L}$, elevated LDL cholesterol levels of 6.9 and $6.4 \mathrm{mmol} / \mathrm{L}$, and serum apo B concentrations of 1.65 and $1.58 \mathrm{~g} / \mathrm{L}$, respectively. The mother of one of these babies also had a high total cholesterol $(9.8 \mathrm{mmol} / \mathrm{L})$, LDL cholesterol $(8.8 \mathrm{mmol} / \mathrm{L})$, and apo B $(1.80 \mathrm{~g} / \mathrm{L})$, which is consistent with the phenotype of familial hypercholesterolemia. The parents of the other infant had normal LDL cholesterol and apo B levels, the mother $3.2 \mathrm{mmol} / \mathrm{L}$ and $0.9 \mathrm{~g} / \mathrm{L}$ and the father $4.3 \mathrm{mmol} / \mathrm{L}$ and $0.94 \mathrm{~g} / \mathrm{L}$, respectively.

Infant group 3. In these infants who had low neonatal apo AI, levels had increased markedly by $8.5 \mathrm{mo}(p<0.001)$. Apo B levels also showed a similar increase $(p<0.01)$. The correlation in apo A-I levels between these two measurements for group 3 infants was not significant (Table 1). Also, levels at 8.5 mo for all infants who had neonatal apo A-I below the 5 th percentile $(n$ $=17$ ) and group 4 infants were not different (Fig. 1, bottom panel). Because group 4 babies had neonatal apo A-I values above the 5 th percentile, this also indicates a regression toward the mean at $8.5 \mathrm{mo}$ in the group 3 babies. In contrast to group 1 and 2 infants, neither the parents of the group 3 infants nor the infants themselves at $8.5 \mathrm{mo}$ had indications of inherited abnormal HDL or apo A-I levels.

Infant group 4. In this group with normal neonatal apolipo- protein levels, apo A-I decreased and apo B and apo B/A-I showed increases at 8.5 mo (Table 1). Notably, apo B levels and apo B/A-I ratios at 8.5 mo were highly correlated with the levels and ratios measured at 2-5 d. However, the correlations in apo $\mathrm{B}$ levels and apo B/A-I ratios between these two times for the other three infant groups were not significant. None of the infants or parents of these group 4 infants had evidence of inherited hypercholesterolemias at the time of recall.

Apolipoproteins and birth weight. We had previously shown that capillary blood apo A-I measured during the 1st week of life was negatively correlated with birth weight (1). When this relationship was reassessed at a mean age of $8.5 \mathrm{mo}$, the significant negative correlation with birth weight was still evident. This negative correlation was statistically significant in group 1 infants ( $r=-0.63, n=13, p=0.021$ ). Negative correlations were also found in the other infant groups, although they were not statistically significant (Table 2). Furthermore, the positive correlation that we had previously observed between capillary blood apo B and the birth weight was also still evident at a mean age of 8.5 mo with differed statistical significances in different groups (Table 2). There was also a significant positive correlation between birth weight and the ratio of apo B/A-I at 8.5 mo of age shown both in group 1 and 4 infants (Table 2), whereas no significant correlation had been found in infants during the first postnatal week (1). There were no correlations between serum apo A-I and B with age when measured between the 5th and 13th mo in any infant subgroups, and no correlations between the infants' birth weight and the apo A-I or apo B levels of the mother or the father.

Parental serum lipid levels. The lipid and apolipoprotein profiles and the ages of the parents are shown in Table 3 . The fathers had higher total cholesterol, LDL cholesterol, triglyceride levels, and total cholesterol to HDL cholesterol ratios and lower HDL cholesterol levels than the mothers. The serum apo B and apo $\mathrm{B} / \mathrm{A}-\mathrm{I}$ levels were also significantly higher in the fathers and the 


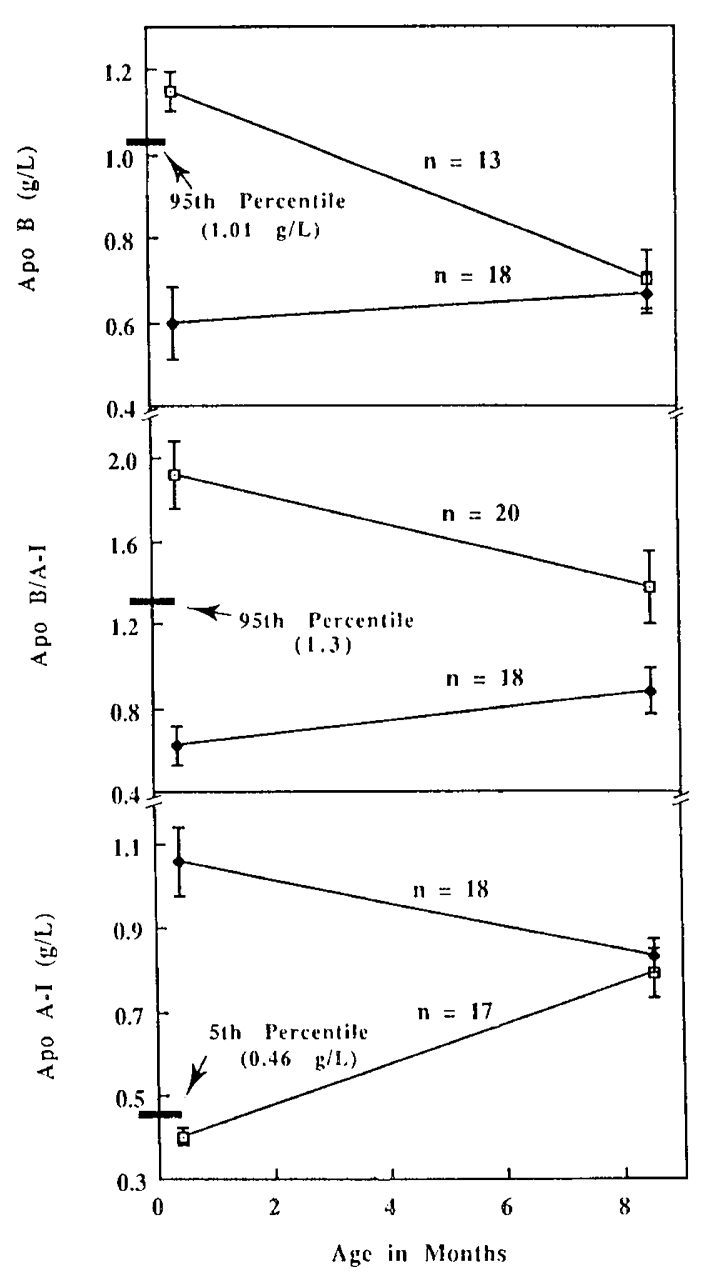

Fig. 1. Serum apolipoprotein levels at the ages of 2 to $5 \mathrm{~d}$ and 5 to $13 \mathrm{mo}(8.5 \pm 2.3 \mathrm{mo})$ in three groups of infants $(\square)$ each compared with the levels in 18 infants who had normal neonatal levels ( ). All values are means \pm SEM. The neonatal serum levels were obtained by assuming a hematocrit of $55 \%$ and multiplying capillary blood values by 2.2 . In the top panel are the changes in 13 babies whose neonatal apo B levels were above the 95 th percentile of the neonatal apo B distribution. The middle panel shows the changes found in all 20 infants whose neonatal apo B/A-I values were above the 95th percentile of the neonatal distribution. The lower panel shows the changes found in all 17 infants whose initial apo A-I levels were below the 5th percentile of the neonatal distribution. The 95th percentiles (upper and middle panels) and the 5th percentile (lower panel) are shown. The 18 infants with normal apolipoproteins had levels of apo B and apo B/A-I below the 95th percentile and apo A-I above the 5th percentile of the respective neonatal distributions among 919 consecutively born babies. At $8.5 \mathrm{mo}$, infants with high neonatal apo B and low neonatal apo A-I had levels not different from those whose neonatal apo B and A-I levels were normal. However, the babies with high neonatal apo B/A-I had significantly higher 8.5 -mo ratios than those in the infants with normal neonatal ratios $(p<0.001)$.

apo A-I levels were lower. These differences were evident in all subgroups of parents in each infant group, although some did not reach statistical significance. Furthermore, these lipoprotein and apolipoprotein levels did not differ among subgroups for both fathers and mothers.

Correlations between cholesterol, triglyceride, and apolipoprotein levels in infants and parents. There were 44 families for whom samples were available for apolipoprotein measurements from both parents and from their infants in the neonatal period and also at a mean age of $8.5 \mathrm{mo}$; for cholesterol and triglyceride measurements as well, there were 43 families. The regression coefficients between infants' apolipoprotein levels and individual
Table 2. Correlations between apo A-I, apo B, and birth weight $(B W)$ among 51 infants aged $8.5 \pm 2.3$ mo

\begin{tabular}{ccccc}
\hline $\begin{array}{c}\text { Infant } \\
\text { groups* }\end{array}$ & $\begin{array}{c}\text { Apo A-I } \\
v s \text { BW }\end{array}$ & $\begin{array}{c}\text { Apo B } \\
v s \text { BW }\end{array}$ & $\begin{array}{c}\text { Apo B/A-I } \\
v s \text { BW }\end{array}$ & $\begin{array}{c}\text { Apo A-I } \\
\text { vs apo B }\end{array}$ \\
\hline Group 1 & -0.63 & 0.513 & 0.582 & -0.838 \\
$(n=13)$ & $(p=0.021)$ & $(p=0.073)$ & $(p=0.037)$ & $(p=0.0003)$ \\
Group 2 & -0.226 & 0.157 & 0.011 & -0.417 \\
$(n=11)$ & $(p=0.504)$ & $(p=0.646)$ & $(p=0.973)$ & $(p=0.203)$ \\
Group 3 & -0.024 & 0.530 & 0.357 & -0.209 \\
$(n=9)$ & $(p=0.952)$ & $(p=0.146)$ & $(p=0.304)$ & $(p=0.589)$ \\
Group 4 & -0.342 & 0.500 & 0.474 & -0.288 \\
$(n=18)$ & $(p=0.164)$ & $(p=0.035)$ & $(p=0.047)$ & $(p=0.24)$ \\
\hline
\end{tabular}

* Infant groups $1-4$ are described in a footnote to Table 1 .

parent and midparent (average of both parents) levels are shown in Table 4, and for cholesterol and triglyceride levels, in Table 5. For apo A-I levels in the families of group 4 infants, there was a significant association between infant and midparent levels, but the only weak associations with individual parents (Table 4). For apo B the association between infants' and fathers' levels was only significant in the families of group 4 infants. For apo B/A-I ratios, there was a significant association between infants and mothers only in the families of group 1 infants. There were no familial associations in triglyceride levels in all of these families (Table 5). HDL cholesterol levels did not show familial aggregation in group 2 infants for father and midparent levels (Table 5). The association of total and LDL cholesterol levels between infants and their parents occurred with different degrees of significance in the families of each of the subgroups (Table 5).

\section{DISCUSSION}

The present results indicate that individual infants with high levels of apo B, low levels of apo A-I, and high apo B/A-I ratios measured during the neonatal period may regress toward mean concentrations for the whole population when remeasured at the age of $8.5 \mathrm{mo}$. The levels in those with high apo B at birth (group 1) decreased significantly during the subsequent 8.5 mo, whereas levels in those with lower initial apo B increased, as illustrated by the results in the group 3 and group 4 infants (Table 1). Also, levels in babies with low neonatal apo A-I (group 3) increased markedly during the $8.5 \mathrm{mo}$; levels in those with higher neonatal apo A-I (groups 1 and 4), however, decreased during the same period (Table 1). These increases and decreases in apo A-I and apo $B$ in the individual infant groups resulted in nonsignificant correlations between measurements at the two times for both apo A-I and apo B (Fig. 1, top and bottom panels). Although there was a significant correlation between apo B levels at these two times in group 4 infants with normal initial levels, the overall trend shown in Figure 1 (top panel) does not suggest tracking. Nevertheless, high apo B measured in the neonatal period did identify dyslipidemia in two infants, whereas low apo A-I alone did not. Although a similar trend also occurred in infants with high neonatal apo B/A-I, there was less overlap in the ratios among different infant groups at 8.5 mo than found with apo A$\mathrm{I}$ and apo $\mathrm{B}$ alone. We have no explanation for the interesting finding of an inverse relationship between apo B and apo A-I levels at $8.5 \mathrm{mo}$, seen particularly in the high apo B (group 1) infants.

When the infants with high initial apo B/A-I were compared with the group 4 infants with normal initial neonatal apo B/A-I at the age of $8.5 \mathrm{mo}$, the ratios in those with high initial neonatal values were still significantly higher $(p<0.001)$ than those of the group 4 infants (Fig. 1, middle panel). Although the correlations in apo B/A-I ratios between these two times were not consistently significant within individual infant groups, the findings shown in Figure 1 provide evidence for tracking of the ratio. This is of considerable interest in view of the predictive value of this ratio for cardiovascular risk $(2,3)$. Lack of statistical signif- 
Table 3. Lipoprotein and apolipoprotein profiles in parents of recalled infants [mean (SD)]*

\begin{tabular}{|c|c|c|c|c|c|c|c|c|c|}
\hline & & Age & Apo A-I & Apo B & Apo B/A-I & $\mathrm{TC}$ & TG & HDL-C & LDL-C \\
\hline \multirow[t]{4}{*}{ Group $1 \dagger$} & Father & 34.6 & 0.95 & 0.95 & 1.02 & 5.33 & 1.45 & 1.29 & 3.38 \\
\hline & $(n=10)$ & $(7.4)$ & $(0.22)$ & $(0.47)$ & $(0.49)$ & $(1.51)$ & $(1.68)$ & $(0.30)$ & $(1.26)$ \\
\hline & Mother & 28.6 & 1.10 & 0.92 & 0.87 & 5.17 & 1.12 & 1.37 & 3.28 \\
\hline & $(n=12)$ & (3.8) & $(0.24)$ & $(0.24)$ & $(0.24)$ & $(0.73)$ & $(0.63)$ & $(0.33)$ & $(0.78)$ \\
\hline \multirow[t]{4}{*}{ Group 2} & Father & 33 & 1.10 & 1.15 & 1.09 & 5.95 & 1.50 & 1.25 & 3.93 \\
\hline & $(n=11)$ & (6.6) & $(0.29)$ & $(0.34)$ & $(0.30)$ & $(0.92)$ & $(0.74)$ & $(0.20)$ & $(0.87)$ \\
\hline & Mother & 30 & 1.19 & $0.84 \ddagger$ & $0.70 \ddagger$ & 5.00 & $0.69 \S$ & $1.63 \S$ & 3.14 \\
\hline & $(n=11)$ & $(3.5)$ & $(0.14)$ & $(0.39)$ & $(0.32)$ & $(1.88)$ & $(0.18)$ & $(0.28)$ & $(1.98)$ \\
\hline \multirow[t]{4}{*}{ Group 3} & Father & 30 & 0.97 & 1.06 & 1.10 & 5.58 & 1.73 & 1.16 & 3.61 \\
\hline & $(n=8)$ & (3.5) & $(0.07)$ & $(0.25)$ & $(0.31)$ & $(1.07)$ & $(2.03)$ & $(0.20)$ & $(0.83)$ \\
\hline & Mother & 28.4 & 1.14 & 0.84 & $0.76^{*}$ & 5.20 & 1.25 & 1.44 & 3.20 \\
\hline & $(n=9)$ & (4.3) & $(0.25)$ & $(0.29)$ & $(0.28)$ & $(1.05)$ & $(0.71)$ & $(0.38)$ & $(0.81)$ \\
\hline \multirow[t]{4}{*}{ Group 4} & Father & 34.8 & 1.07 & 1.08 & 1.07 & 6.12 & 1.62 & 1.34 & 4.06 \\
\hline & $(n=17)$ & $(4.0)$ & $(0.25)$ & $(0.34)$ & $(0.43)$ & $(1.14)$ & $(0.83)$ & $(0.48)$ & $(1.08)$ \\
\hline & Mother & 32 & $1.46 \S$ & $0.78 \S$ & $0.59 \|$ & 5.38 & 0.96 & $1.89 \|$ & 3.06 \\
\hline & $(n=18)$ & (3.8) & $(0.64)$ & $(0.23)$ & $(0.21)$ & $(0.96)$ & $(0.43)$ & $(0.23)$ & $(0.92)$ \\
\hline
\end{tabular}

* TC, total cholesterol; TG, triglyceride; HDL-C, HDL cholesterol; and LDL-C, LDL cholesterol.

+ Infant groups $1-4$ are described in a footnote to Table 1.

$\ddagger 0.05>p>0.01$.

$\S p<0.01$.

$\| p<0.001$.

Table 4. Regression coefficients (SEM) between serum apo A-I and $B$ concentrations and the apo $B / A-I$ ratio in parents (individual and combined) and their infants when aged $8.5 \pm 2.3 \mathrm{mo}$

\begin{tabular}{|c|c|c|c|c|}
\hline & Infants* & Mother & Father & $\begin{array}{c}\text { (Mother + } \\
\text { father)/2 }\end{array}$ \\
\hline \multirow[t]{4}{*}{ Apo A-I } & $\begin{array}{l}\text { Group } 1 \\
(n=9)\end{array}$ & $0.5(0.23) \dagger$ & $-0.06(0.29)$ & $0.55(0.30)$ \\
\hline & $\begin{array}{l}\text { Group } 2 \\
(n=11)\end{array}$ & $0.30(0.18)$ & $0.03(0.28)$ & $0.51(0.33)$ \\
\hline & $\begin{array}{l}\text { Group } 3 \\
(n=8)\end{array}$ & $0.03(0.30)$ & $1.08(1.02)$ & $0.87(0.59)$ \\
\hline & $\begin{array}{l}\text { Group } 4 \\
(n=16)\end{array}$ & $0.25(0.2)$ & $0.39(0.20) \dagger$ & $0.65(0.24) \ddagger$ \\
\hline \multirow[t]{4}{*}{ Apo B } & $\begin{array}{l}\text { Group } 1 \\
(n=9)\end{array}$ & $0.43(0.30)$ & $-0.08(0.16)$ & $0.13(0.24)$ \\
\hline & $\begin{array}{l}\text { Group 2 } \\
(n=11)\end{array}$ & $-0.30(0.35)$ & $0.62(0.32) \dagger$ & $0.44(0.56)$ \\
\hline & $\begin{array}{l}\text { Group } 3 \\
(n=8)\end{array}$ & $-0.31(0.21)$ & $0.32(0.24)$ & $-0.08(0.35)$ \\
\hline & $\begin{array}{l}\text { Group } 4 \\
(n=16)\end{array}$ & $-0.25(0.14)$ & $0.22(0.09) \S$ & $0.18(0.19)$ \\
\hline \multirow[t]{4}{*}{ Apo B/A-I } & $\begin{array}{l}\text { Group 1 } \\
(n=9)\end{array}$ & $1.03(0.32) \neq$ & $-0.14(0.22)$ & $0.51(0.43)$ \\
\hline & $\begin{array}{l}\text { Group 2 } \\
(n=11)\end{array}$ & $0.44(0.52)$ & $1.30(0.87)$ & $1.83(1.52)$ \\
\hline & $\begin{array}{l}\text { Group } 3 \\
(n=8)\end{array}$ & $0.08(0.51)$ & $0.72(0.45)$ & $0.87(0.59)$ \\
\hline & $\begin{array}{l}\text { Group } 4 \\
(n=16)\end{array}$ & $0.05(0.34)$ & $0.22(0.15)$ & $0.38(0.25)$ \\
\hline
\end{tabular}

* Infant groups $1-4$ are described in a footnote to Table 1 .

$\dagger 0.10>p>0.05$.

$\ddagger p<0.01$.

$\S 0.05>p>0.01$.

icance in apo B/A-I ratios between these two times in subgroups 1,2 , and 3 could be due to small sample sizes in the subgroups. It is noteworthy that a high apo B/A-I ratio measured in the neonatal period did identify two infant families with familial hypercholesterolemia lipid profiles.

There may be several reasons for the tracking of the ratio and not of the individual apolipoprotein levels. The ratio measurements are obtained from the one dried blood spot extract so that possible errors in quantitation of the individual apolipoproteins are minimized, as Micic et al. (11) have documented. Some attenuation of the effects of variables on individual apolipoprotein levels may also result from the use of the ratio. Perinatal factors may transiently affect apolipoprotein levels in the first few postnatal days $(12,13)$. Greater variabilities in the dried blood spot assays for apo B and apo A-I measurements during first few days of life would also be attributable to the weak correlations in apo B and apo A-I levels at these two times. This may be largely responsible for the regression toward mean levels in some infants during the 1st year of life.

Despite the absence of a significant correlation between apo B measured during the 1st week of life and at a mean age of 8.5 mo, two infants from the top neonatal $5 \%$ of the apo B distribution did have persisting hyperapo $\mathrm{B}$, and in one there were high values for apo B and LDL cholesterol in one parent as well; only the mother of the other infant was available for study, and her levels were not elevated. The two infants identified with the phenotype of familial hypercholesterolemia were from among the top $5 \%$ of the apo B/A-I distribution. The absence of high levels in the parents of one of those infants is not explained, although nonpaternity or a new mutation might be possibilities inasmuch as the infant's levels of apo B and LDL cholesterol $(1.58 \mathrm{~g} / \mathrm{L}$ and $6.4 \mathrm{mmol} / \mathrm{L}$, respectively) were consistent with the phenotype of familial hypercholesterolemia. It should be emphasized that the low response $(31 \%)$ to the recall in our study makes predictions about the prevalence of dyslipidemia during the 1st year of life uncertain. The families who responded may have had prior knowledge of a family history of hyperlipidemia or premature heart disease. However, the data are consistent with familial hypercholesterolemia occurring in about 1 in 500 infants.

Our data and also those reported by Sveger et al. (14) suggest that using both a high apo B/A-I ratio and a high apo B should improve the detection of both familial hypercholesterolemia and hyperapo B. The latter is also associated with increased cardiovascular risk $(15,16)$ and when detected in infancy may indicate the early expression of the dominantly inherited familial combined hyperlipoproteinemia (17). In contrast to the findings for apo B and apo B/A-I ratio, low apo A-I alone detected in the 1st week of life was not in this study predictive of familial dyslipidemia. This was despite the significant but weak correlation we found between levels in infants at $1 \mathrm{wk}$ and $8.5 \mathrm{mo}$ and between parental and infant levels when the infants were aged $8.5 \mathrm{mo}$. The latter significant correlation for apo A-I was also found by Hamsten et al. (18) in a study of 85 Swedish families. 
Table 5. Regression coefficients (SEM) between serum total cholesterol, triglyceride, HDL cholesterol, and LDL cholesterol concentrations in parents (individual and combined) and their infants at age $8.5 \pm 2.3 \mathrm{mo}^{*}$

\begin{tabular}{|c|c|c|c|c|}
\hline & Infants $\dagger$ & Mother & Father & $\begin{array}{c}\text { (Mother + } \\
\text { father) } / 2 \\
\end{array}$ \\
\hline \multirow[t]{4}{*}{$\mathrm{TC}$} & $\begin{array}{l}\text { Group 1 } \\
(n=9)\end{array}$ & $1.48(0.36) \ddagger$ & $-0.07(0.17)$ & $0.64(0.50)$ \\
\hline & $\begin{array}{l}\text { Group } 2 \\
(n=11)\end{array}$ & $0.94(0.29) \S$ & $-0.15(0.53)$ & $1.37(0.55) \S$ \\
\hline & $\begin{array}{l}\text { Group } 3 \\
(n=8)\end{array}$ & $-0.55(0.26)$ & $0.37(0.25)$ & $-0.14(0.43)$ \\
\hline & $\begin{array}{l}\text { Group 4 } \\
(n=15)\end{array}$ & $-0.10(0.34)$ & $0.14(0.24)$ & $0.10(0.32)$ \\
\hline \multirow[t]{4}{*}{ LDL-C } & $\begin{array}{l}\text { Group } 1 \\
(n=9)\end{array}$ & $0.87(0.40) \|$ & $0.20(0.25)$ & $0.86(0.36)$ \\
\hline & $\begin{array}{l}\text { Group } 2 \\
(n=11)\end{array}$ & $0.72(0.25) \S$ & $-0.09(0.53)$ & $1.26(0.52) \S$ \\
\hline & $\begin{array}{l}\text { Group } 3 \\
(n=8)\end{array}$ & $-0.59(0.38)$ & $0.30(0.38)$ & $-0.28(0.48)$ \\
\hline & $\begin{array}{l}\text { Group } 4 \\
(n=15)\end{array}$ & $0.26(0.28)$ & $-0.09(0.18)$ & $0.04(0.29)$ \\
\hline \multirow[t]{4}{*}{ TG } & $\begin{array}{l}\text { Group } 1 \\
(n=9)\end{array}$ & $0.43(0.51)$ & $-0.24(0.20)$ & $-0.20(0.33)$ \\
\hline & $\begin{array}{l}\text { Group } 2 \\
(n=11)\end{array}$ & $-0.56(0.85)$ & $0.28(0.29)$ & $0.32(0.48)$ \\
\hline & $\begin{array}{l}\text { Group } 3 \\
(n=8)\end{array}$ & $-0.15(0.22)$ & $0.18(0.07)$ & $0.25(0.14)$ \\
\hline & $\begin{array}{l}\text { Group } 4 \\
(n=15)\end{array}$ & $1.04(0.78)$ & $0.13(0.45)$ & $0.85(0.57)$ \\
\hline \multirow[t]{4}{*}{ HDL-C } & $\begin{array}{l}\text { Group 1 } \\
(n=9)\end{array}$ & $0.20(0.20)$ & $-0.07(0.23)$ & $0.15(0.19)$ \\
\hline & $\begin{array}{l}\text { Group } 2 \\
(n=11)\end{array}$ & $0.23(0.13)$ & $0.56(0.21) \S$ & $0.64(0.24) \S$ \\
\hline & $\begin{array}{l}\text { Group } 3 \\
(n=8)\end{array}$ & $-0.06(0.53)$ & $0.28(0.09)$ & $0.10(0.7)$ \\
\hline & $\begin{array}{l}\text { Group } 4 \\
(n=15)\end{array}$ & $0.24(0.43)$ & $0.33(0.27)$ & $0.60(0.43)$ \\
\hline
\end{tabular}

* TC, total cholesterol; LDL-C, LDL cholesterol; TG, triglyceride; and HDL-C, HDL cholesterol.

$\dagger$ Infant groups 1-4 are described in a footnote to Table 1.

$\ddagger p<0.01$.

$\S 0.05>p>0.01$.

$\| 0.10>p>0.05$

There is also evidence in the study for persisting effects of birth weight on the levels of individual apolipoproteins. The negative correlation of apo A-I levels with birth weight and the positive correlation of apo $\mathrm{B}$ that had been demonstrated in the neonatal period (1) were also present at 8.5 mo. The persistence of these birth weight effects is intriguing. Although we have no explanation for the findings, it is interesting that Sveger et al. (19) also found a negative effect of birth weight on apo A-I levels when these were measured in 10- to 11-yr-old children. In their series, obese 10- to 11-yr-old children had higher apo B levels and higher apo B/A-I ratios than nonobese children, although no correlation between apo B and birth weight was documented (19). However, both of these findings are in accordance with those of our study relating to a persisting effect of birth weight on circulating apolipoprotein levels in infancy and childhood. We were unable to determine whether our apolipoprotein findings were independent of gestational age. This is clearly relevant because if that were so it would suggest that this continuing effect is unrelated to reduced fetal growth. This was the case for the inverse relation between systolic blood pressure and birth weight documented by Barker et al. (20) for 10-yr-old children and adults. Thus, although we do not have explanations for the mechanisms, there appears to be an association between birth weight and both lipid metabolism and blood pressure in later life.

In conclusion, our findings suggest that measuring apo $B$ and the apo B/A-I ratio in infancy could facilitate detection of infants and parents with familial hypercholesterolemia and hyperapo B and facilitate family-based coronary prevention. When combined with apo(a) measurements (21), a more precise definition of cardiovascular risk and need for prevention should be possible and could be used in older children. The study also documents the persistence of an association between birth weight and apo A-I and apo B levels during the 1 st year of life and in inverse relationship between apo B and apo A-I levels at the age of 8.5 mo.

Acknowledgments. The authors thank Dr. Mary O'Halloran, Director of the Department of Biochemistry, Royal Alexandria Hospital for Children, Sydney, for serum cholesterol and triglyceride measurements in the infants and Judith Lynch for help in arranging the recall of infants and their parents.

\section{REFERENCES}

1. Wang XL, Wilcken DEL, Dudman NPB 1990 Neonatal apo A-I and B and apo(a) in dried blood spots in an Australian population. Pediatr Res 28:496501

2. Brunzell HD, Sniderman AD, Alber JJ, Kwiterovich Jr PO 1984 Apoproteins $\mathrm{B}$ and $\mathrm{A}-\mathrm{I}$ and coronary artery disease in humans. Arteriosclerosis 4:79-83

3. Snidermann AD 1988 Apolipoprotein B and apolipoprotein A-I as predictors of coronary artery disease. Can J Cardiol 4(suppl A):24A-30A

4. Albers JJ, Brunzell JD, Knapp RH 1989 Apoprotein measurements and their clinical application. Clin Lab Med 9:137-152

5. Wilcken DEL, Blades BL, Dudman NPB 1988 A neonatal screening approach to the detection of familial hypercholesterolaemia and family-based coronary prevention. J Inherited Metab Dis 11(suppl 1):87-90

6. Blades BL, Dudman NPB, Wilcken DEL 1987 Variables affecting apolipoprotein B measurements in 3- to 5-d-old babies: a study of 4491 neonates. Pediatr Res 21:608-614

7. Blades BL, Dudman NPB, Wilcken DEL 1988 Screening for familial hypercholesterolemia in 5000 neonates: a recall study. Pediatr Res 23:500-504

8. Wang XL, Dudman NPB, Blades BL, Wilcken DEL 1989 Changes in the immunoreactivity of apo A-I during storage. Clin Chim Acta 179:285-294

9. Wang XL, Dudman NPB, Wilcken DEL 1989 Enzyme-linked immunosorban assay of apolipoprotein B in dried blood spotted onto filter paper, suitable for neonatal screening. Clin Chem 35:2082-2086

10. Kirkpatrick BV, Mueller DG 1983 The newborn infant. In: Maurer HM (ed) Pediatrics. Churchill Livingstone, New York, pp 51-93

11. Micic S, Arends J, Norgaad-Pedersen B, Christoffersen K. Andersen GE 1988 Simultaneous quantification by double rocket immunoelectrophoresis of apolipoproteins A-I and B in blood spotted on filter paper. Clin Chem 34:2452-2455

12. Lane DM, McConathy WJ 1983 Factors affecting the lipid and apolipoproteins levels of cord sera. Pediatr Res 17:83-91

13. Lane DM, McConathy WJ 1986 Changes in the serum lipids and apolipoprotein levels in the first four weeks of life. Pediatr Res 20:332-337

14. Sveger T, Fex G, Flodmark C-E, Kjellstrom T, Borgfors N 1990 Apolipoprotein A-I:B ratio and B screening: a preliminary study of 10- and 11-year-old children. J Pediatr Gastroenterol Nutr 10:179-184

15. Sniderman AD, Wolfson C, Teng B, Franklin FA, Bachorik PS, Kwiterovich Jr PO 1982 Association of hyperapobetalipoproteinemia with endogenous hypertriglyceridemia and atherosclerosis. Ann Intern Med 97:833-839

16. Sniderman A, Shapiro S, Marpole D, Skinner B, Teng B, Kwiterovich Jr PO 1980 Association of coronary atherosclerosis with hyperapobetalipoproteinemia [increased protein but normal cholesterol levels in human plasma low density (B) lipoproteins]. Proc Natl Acad Sci USA 77:604-608

17. Grundy SM, Chait A, Brunzell JD 1987 Familial combined hyperlipidemia workshop. [meeting summary] Arteriosclerosis 7:203-207

18. Hamsten A Iselius L, Dahlen G de Faire U 1986 Genetic and cultural inheritance of serum lipids, low and high density lipoprotein cholesterol and serum apolipoprotein A-I. A-II and B. Atherosclerosis 60:199-208

19. Sveger T, Flodmark C-E, Fex G, Henningsen NC 1989 Apolipoproteins A-I and $B$ in obese children. J Pediatr Gastroenterol Nutr 9:497-501

20. Barker DJP, Osmond C, Golding J, Kuh D, Wadsworth MEJ 1989 Growth in utero, blood pressure in childhood and adult life, and mortality from cardiovascular disease. Br Med J 298:564-567

21. Wang XL, Wilcken DEL, Dudman NPB 1992 Early expression of the apolipoprotein(a) gene: relationships between infants' and their parents' serum apolipoprotein(a) levels. Pediatrics (in press) 